\title{
Aggressive Gastric Carcinoma Producing Alpha-Fetoprotein: A Case Report and Review of the Literature
}
A. Lunghi ${ }^{a}$
P. Petreni $i^{a}$
R.G. Romanelli ${ }^{\text {b }}$
F. Vizzutti ${ }^{\text {b }}$
F. Marra ${ }^{b}$
R. Tarquini ${ }^{b}$
G. Laffi ${ }^{b}$

a'Dipartimento di Oncologia, Oncologia Medica, Azienda Ospedaliero-Universitaria Careggi, and ${ }^{\mathrm{b}}$ Dipartimento di Medicina Interna, Medicina ed Epatologia, Azienda Ospedaliero-Universitaria Careggi, Florence, Italy

\section{Key Words}

Alpha-fetoprotein · Gastric cancer · Tumor marker · Liver metastases

\begin{abstract}
A 65-year-old man presented to our hospital with abdominal pain, dyspepsia and anorexia. Laboratory tests showed an altered liver function and abdomen ultrasonography revealed multiple liver nodules, suspected to be metastatic lesions. Serous tumor markers were elevated and a very high level of alpha-fetoprotein was found. Computer tomography confirmed the hepatic lesions and disclosed a thickening of the lesser curvature of the gastric wall. A subsequent endoscopy showed an ulcer on the lesser curvature. Biopsies taken from the gastric ulcer and the liver nodule revealed an adenocarcinoma, both of gastric origin. Shortly after the diagnosis, the patient's condition worsened and he died only 15 days later. This case report illustrates how alpha-fetoprotein-producing gastric adenocarcinomas have a high incidence of venous and lymphatic invasion and a rapid hepatic spread with a very poor prognosis.

(c) 2014 S. Karger AG, Basel
\end{abstract}

\section{Case Presentation}

In September 2011, a 65-year-old Caucasian man was admitted to our hospital after a 1month history of epigastric pain, dyspepsia, and anorexia. He had been treated with a proton-pump inhibitor for 2 months. He had a history of type 2 diabetes mellitus, arterial 
Lunghi et al.: Aggressive Gastric Carcinoma Producing Alpha-Fetoprotein: A Case Report and Review of the Literature

hypertension, and dyslipidemia. At physical examination, intense abdominal pain in the upper abdominal quadrants was noted. Laboratory tests showed elevated aspartate transaminase $107 \mathrm{U} / \mathrm{l}$ (reference range 10-40 U/l), alanine transaminase $89 \mathrm{U} / \mathrm{l}$ (reference range 10-40 U/l), gamma-glutamyl transpeptidase $627 \mathrm{U} / \mathrm{l}$ (reference range 10-40 U/l) and alkaline phosphatase $309 \mathrm{U} / \mathrm{l}$ (reference range 40-130 U/l); total bilirubin was $1.07 \mathrm{mg} / \mathrm{dl}$ (reference range $0.3-1.0 \mathrm{mg} / \mathrm{dl}$ ). Ultrasonography showed a remarkable and irregular enlargement of the liver with multiple and diffuse nodules in the right hepatic lobe (the largest measured $5 \mathrm{~cm}$ in diameter) and a unique large mass $(15 \times 9 \mathrm{~cm})$ in the left lobe. Abdomen computer tomography scans showed multiple nodules in the liver, suspected to be metastatic lesions, portal vein thrombosis, multiple adenopathies along the lesser curvature of the stomach, the mesenteric root and the lombo-aortic region as well as a thickening of the gastric lesser curvature wall (fig. $1 \mathrm{a}, \mathrm{b}$ ). Tumor markers were: alpha-fetoprotein (AFP) $209093 \mathrm{U} / \mathrm{ml}$ (reference range 0-10 U/ml), Ca 19.9 170,5 U/ml (reference range 0-39 $\mathrm{U} / \mathrm{ml}$ ), and Ca $12552,2 \mathrm{U} / \mathrm{ml}$ (reference range $035 \mathrm{U} / \mathrm{ml}$ ); other markers were found to be in a normal range, in particular CEA and Ca 72.4. Markers for hepatitis B and C were negative (HBsAg, HBV-DNA and HCV IgG). An esophagogastroduodenoscopy showed a $4 \mathrm{~cm}$ ulcer on the lesser curvature of the stomach (fig. 2). At the pathologic examination, the biopsy revealed a gastric adenocarcinoma. The biopsy of one of the hepatic nodules showed a poorly differentiated adenocarcinoma, similar to that of a gastric biopsy. Immunohistochemical findings showed a positivity for CAM 5.2, CDX 2 CK 20 and a negativity for CD10, TTF1, sinaptophysin and chromogranin A, therefore supporting a diagnosis of metastasis of gastric adenocarcinoma (fig. 3). One week later, the patient's condition quickly worsened (Performance Status 3 in accordance with the European Cooperative Oncology Group scale). He presented jaundice, abdominal pain and, at palpation, the appearance of a solid mass in the left upper quadrant of the abdomen and liver enlargement. Levels of transaminases, gammaglutamyl transpeptidase and alkaline-phosphatase increased; total bilirubin was $19.6 \mathrm{mg} / \mathrm{dl}$ and the conjugated one was $12.8 \mathrm{mg} / \mathrm{dl}$. Abdominal ultrasonography showed, with respect to the previous one, an increased number and size of the hepatic nodules as well as a biliary tract dilatation. Tumor markers were found to be increased further: AFP $470396 \mathrm{U} / \mathrm{ml}, \mathrm{Ca}$ $19.9354 .0 \mathrm{U} / \mathrm{ml}$, and Ca $125113.7 \mathrm{U} / \mathrm{ml}$. A chemotherapeutic approach was excluded due to the patient's poor condition, his performance status and the altered liver function tests. The patient was discharged and received the best possible supportive care. He died 15 days later.

\section{Discussion}

Gastric adenocarcinoma is a neoplasm with a frequent association to various tumor markers such as Ca 72.4, CEA and Ca 19.9. In our case report, elevated serum AFP levels were present in a patient with gastric adenocarcinoma and liver metastases. AFP is a wellknown embryonic serum protein, produced by fetal liver cells, yolk sac cells and some fetal gastrointestinal cells [1]. The elevation of serum AFP, in conjunction with the hepatic lesions, may be associated with hepatocellular carcinoma or germ-cell tumors. However, AFP can be produced exceptionally by gastrointestinal tract organs [1], the lung [2], the bladder [3] and by renal cancers [4]. For diseases such as chronic hepatitis, liver cirrhosis and hepatocellular carcinoma, the level of AFP is a good predictor of disease progression and outcome, as it is directly correlated to disease progression $[5,6]$.

Gastric cancer with the capability of releasing AFP is called AFP-producing gastric carcinoma, first described by Boureille et al. [7] in 1970. Only a few cases have been reported with an incidence rate of $2.7-8.0 \%$ of all gastric malignant tumors [8]. The majority of cases 
Lunghi et al.: Aggressive Gastric Carcinoma Producing Alpha-Fetoprotein: A Case Report and Review of the Literature

described in the literature refer to Asian people [9]. Our case is one of the few European cases of AFP-producing gastric carcinomas. However, the serum AFP level does not necessarily correlate with tumor size, stage or prognosis $[6,8,10]$. In our case, elevated serum levels of AFP and his quick increase were associated with a rapid disease progression and a fatal outcome.

Cases of AFP-producing gastric cancers are characterized by a poor prognosis, a high incidence of venous invasion, by lymph node and liver metastases and even T1 tumors (according to the TNM staging system) [5]. The exact molecular mechanisms explaining this aggressive behavior is still unclear. Possible causes of liver metastases have been hypothesized in the hepatic capability to develop a suitable environment for the cancer cells growth and to promote an early vascular invasion [5].

\section{Conclusions}

AFP-producing gastric cancers are a small subgroup of gastric cancers, with a high likelihood of rapid hepatic metastasization. We think that further studies, especially on a cellular and molecular level, are necessary to explain the highly aggressive biological behavior of AFP-producing gastric cancers in order to develop an effective multimodal and targeted therapy.

\section{Acknowledgements}

The authors would like to thank the Department of Internal Medicine, Internal Medicine and Liver Unit, Azienda Ospedaliero-Universitaria Careggi, School of Medicine, University of Florence, Florence, Italy, and Umberto Arena, MD, ultrasonography consultant. We also thank Simonetta Viviani, MD, for her contribution in the production of this paper.

\section{Disclosure Statement}

The authors declare that there are no conflicts of interest regarding the publication of this paper.

\section{References}

1 Gitlin D, Pericelli A, Gitlin G: Synthesis of alpha-fetoprotein by liver, yolk sac and gastrointestinal tract of the human conceptus. Cancer Res 1972;32:979-982.

- Hiroshima K, Iyoda A, Toyozaki T, Haga Y, Baba M, Fujisawa T, Ishikura H, Ohwada H: Alpha-fetoproteinproducing lung carcinoma: report of three cases. Pathol Int 2002;52:46-53.

-3 Takayama H: A case of bladder cancer producing alpha-fetoprotein (AFP) (in Japanese). Hinyokika Kiyo 1995;41:387-389.

4 Morimoto H, Tanigawa N, Inoue H, Muraoka R, Hosokawa Y, Hattori T: Alpha-fetoprotein-producing renal cell carcinoma. Cancer 1988;61:84-88.

5 Liu X, Cheng Y, Sheng W, Lu H, Xu Y, Long Z, Zhu H, Wang Y: Clinicopathologic features and prognostic factors in alpha-fetoprotein-producing gastric cancers: analysis of 104 cases. J Surg Oncol 2010;102:249255.

6 Inoue M, Sano T, Kuchiba A, Taniguchi H, Fukagawa T, Katai H: Long-term results of gastrectomy for alphafetoprotein-producing gastric cancer. Br J Surg 2010;97:1056-1061.

-7 Bourreille J, Metayer P, Sauger F, Matray F, Fondimare A: Existence of alpha feto protein during gastricorigin secondary cancer of the liver (in French). Presse Med 1970;78:1277-1278. 


\section{Case Reports in Oncology}

\begin{tabular}{l|l}
\hline Case Rep Oncol 2014;7:92-96 & \multicolumn{2}{l}{} \\
\hline DOI: $10.1159 / 000358509$ & $\begin{array}{l}\text { C 2014 S. Karger AG, Basel } \\
\text { www.karger.com/cro }\end{array}$ \\
\hline
\end{tabular}

Lunghi et al.: Aggressive Gastric Carcinoma Producing Alpha-Fetoprotein: A Case Report and Review of the Literature

8 Kono K, Amemiya H, Sekikawa T, Iizuka H, Takahashi A, Fujii H, et al: Clinicopathologic features of gastric cancers producing alpha-fetoprotein. Dig Surg 2002;19:359-365.

-9 Li XD, Wu CP, Ji M, Wu J, Lu B, Shi HB, Jiang JT: Characteristic analysis of $\alpha$-fetoprotein-producing gastric carcinoma in China. World J Surg Oncol 2013;11:246.

10 Adachi Y, Tsuchihashi J, Shiraishi N, Yasuda K, Etoh T, Kitano S: AFP-producing gastric carcinoma: multivariate analysis of prognostic factors in 270 patients. Oncology 2003;65:95-101.

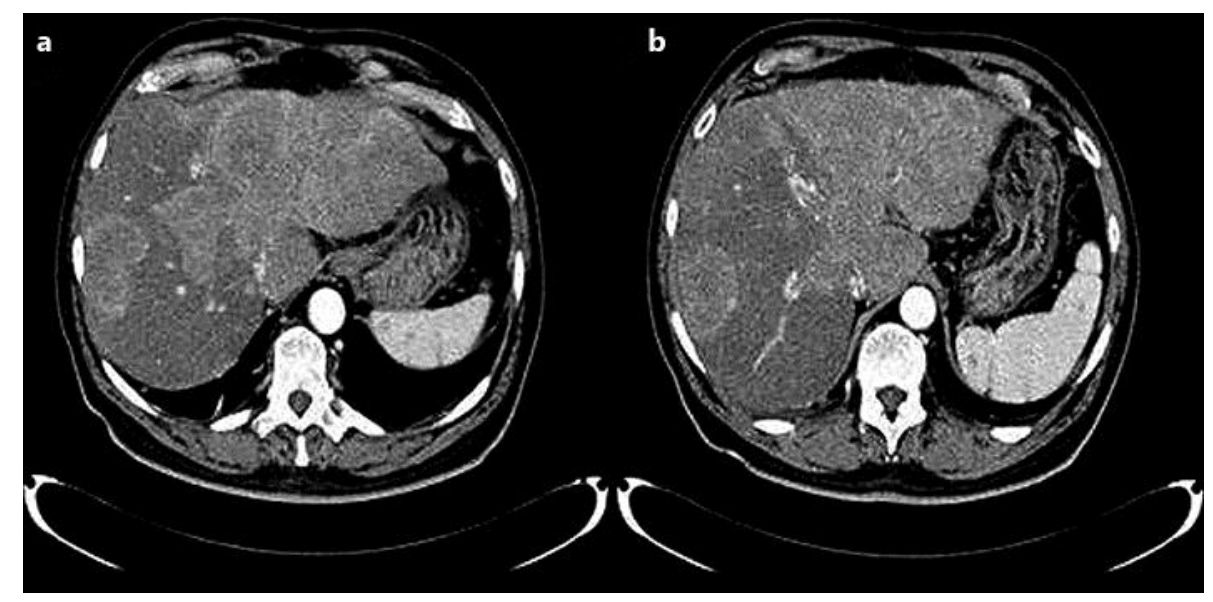

Fig. 1. Computer tomography image of metastatic lesions in the liver (a, b).

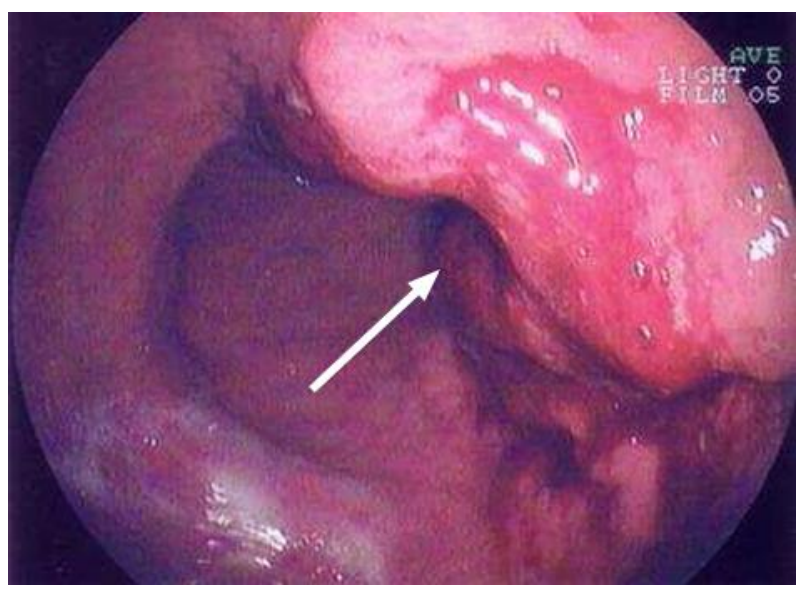

Fig. 2. Esophagogastroduodenoscopy image of a bleeding gastric ulcer (see arrow). 


\section{Case Reports in Oncology}

Lunghi et al.: Aggressive Gastric Carcinoma Producing Alpha-Fetoprotein: A Case Report and Review of the Literature

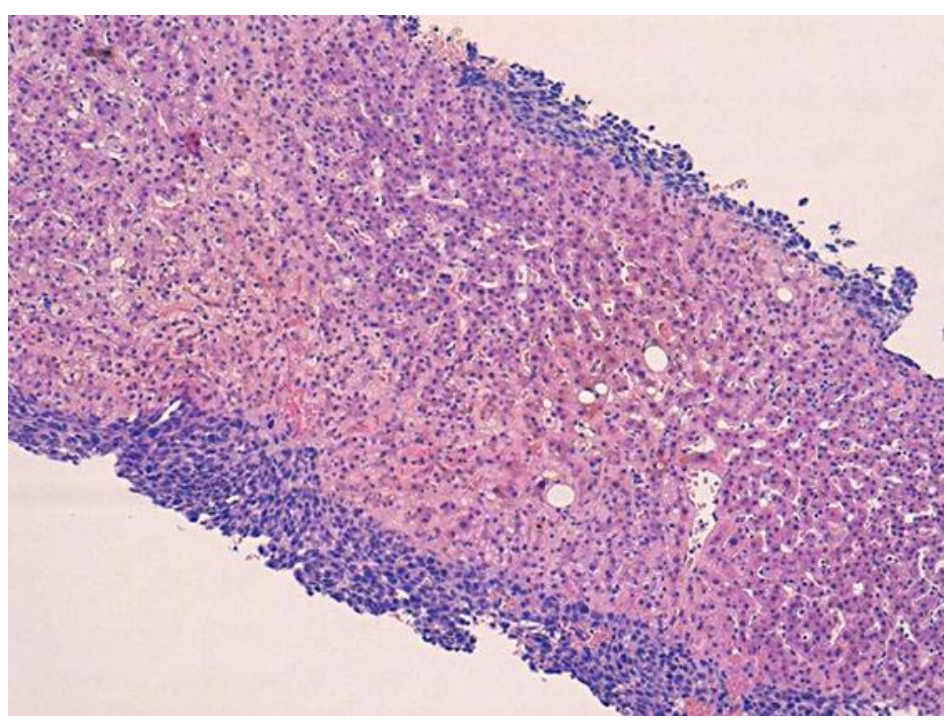

Fig. 3. Histologic evaluation of the hepatic biopsy. 